\title{
Simulation of energy evolution during deformation failure process of the layer-intact structure
}

\author{
Tan Yan ${ }^{1}$, Tan Yunliang ${ }^{1}$, Guo Weiyao*1, Alexey Renev ${ }^{2}$, and Danil Zorkov ${ }^{2 *}$ \\ 1. College of Energy and Mining Engineering, Shandong University of Science and Technology, \\ Qingdao 266590, China \\ 2. T. F. Gorbachev Kuzbass State Technical University, 650000, 28 Vesennyaya St., Kemerovo, \\ Russia
}

\begin{abstract}
To research the failure mechanism of the layer-crack structure of surrounding rock in deep mine roadway, the combination (Layer-Intact structure) of shallow layer-crack coal and deep complete coal was taken as the research object, and the mechanical behavior and energy evolution law of the Layer-Intact structure under uniaxial and biaxial compression were studied by numerical simulation with particle flow code $\left(\mathrm{PFC}^{2 \mathrm{D}}\right)$. The results show that: (1) In the Layer-Intact structure, layer-crack specimen is destroyed prior to intact specimen; The degree of fragmentation increases with the increase of confining stress, and decreases with the increase of fissure number; (2) The confining stress and the fissure number have a significant impact on the basic mechanical parameters of the Layer-Intact structure. The peak stress of the structure increases first and then decreases with the increase in the confining stress, and decreases with the increase in the fissure number; (3) When fissure number is constant, the energy ratio of layer-crack specimen (strain energy stored in the layer-crack specimen to the the whole specimen) increases first and then decreases with the increase in confining stress, while the energy ratio of intact specimen (strain energy stored in the intact specimen to the whole specimen) decreases first and then increases. When the confining stress is constant, with the increase in the fissure number, energy storage capacity of the Layer-Intact structure is reduced, the energy ratio of layer-crack specimen decreases, while the energy ratio of intact specimen increases. The research can provide some reference for revealing the energy release for dynamic instability of layer-crack structure.
\end{abstract}

\section{Introduction}

Under the influence of excavation disturbance, the joints and fracture in the surrounding rock develop continuously, which form the layer-crack structure in the roadside. The layer-crack structure may lead to spalling, and even dynamic disasters, such as rock burst,

\footnotetext{
*Corresponding author: zorkovdv@kuzstu.ru
} 
which seriously threatens the safety of mine production ${ }^{[1-3]}$. Therefore, it is necessary to study the failure mechanism of the layer-crack structure.

At present, many scholars have carried out a lot of researches on the instability of the layer-crack structure using many methods such as numerical simulation、 laboratory test ${ }^{[4-6]}$. For example, Zhang ${ }^{[7]}$ used PFPA to investigate the spalling and failure of surrounding rock in stratified rock mass; $\mathrm{Lu}^{[8-9]}$ simulated the forming process of the layered crack and failure structure and the effect of roof lithology on forming this structure during excavation by using the software LS-DYNA.

The dynamic instability mechanism of the layer-crack structure was analyzed from several aspects. The research object mainly focused on shallow layer-crack coal mass, but the deep intact coal mass also played an important role on the layer-crack structure failure. Therefore, we investigated the instability mechanism of the Layer-Intact structure system composed of deep intact coal mass and shallow layer-crack coal mass with $\mathrm{PFC}^{2 \mathrm{D}}$, and further reveal the failure and energy release law of the Layer-Intact structure.

\section{Model establishment and simulation scheme}

According to the fissure number, the model of Layer-Intact structure is divided into three types, as shown in Fig. 1. The height and width of numerical specimen were $100 \mathrm{~mm}$ and $50 \mathrm{~mm}$, respectively. The numerical specimen was discretized into 23387 particles. The particle size followed a uniform distribution varying from 0.3 to $0.4 \mathrm{~mm}$. After generating the specimen, layer-crack rock models were established by deleting ball particles. Uniaxial and biaxial compression tests were carried out for each type of composite structure model with four different confining stresses, i.e. confining stress of $0,5 \mathrm{MPa}, 10 \mathrm{MPa}$ and $20 \mathrm{MPa}$. According to the research of Zhang ${ }^{[10]}$, the loading rate of $0.05 \mathrm{~m} / \mathrm{s}$ was chosen in this numerical simulation and the loading was applied until the failure occurred.
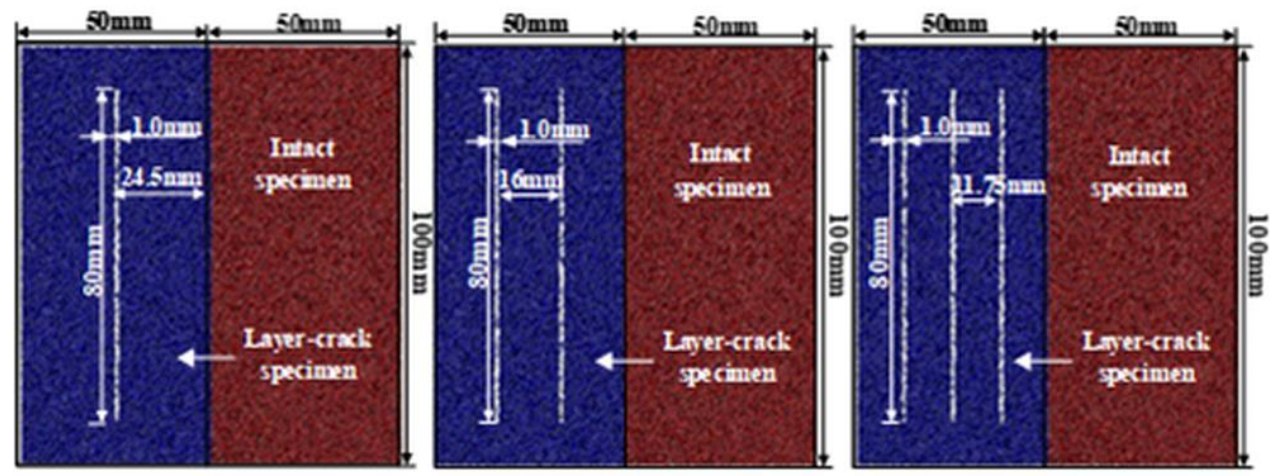

Fig. 1. Particle flow model of Layer-Intact structure specimen

The final micro-parameters are shown in Table 1.The energy of the paper refer to strain energy, and is calculated by default programming.

Table 1. Microscopic mechanical parameters of the specimen

\begin{tabular}{cc}
\hline Parameters & Values \\
\hline Elastic modulus of the particle, $E_{\mathrm{c}} / \mathrm{GPa}$ & 12.3 \\
Parallel-bond radius multiplier & 1.0 \\
Ratio of normal to shear stiffness of the particle,$k_{\mathrm{n}} / k_{\mathrm{s}}$ & 2.5
\end{tabular}


Ratio of normal to shear stiffness of the parallel bond, $k_{\mathrm{n}} / \bar{k}_{\mathrm{s}}$

Particle friction coefficient, $\mu$

Parallel-bond normal strength, $\sigma_{\mathrm{n}} / \mathrm{MPa}$

108.3

Parallel-bond shear strength, $\tau_{\mathrm{n}} / \mathrm{MPa}$

\section{Analysis of simulation results}

\subsection{Strength deformation and failure characteristics}

Figure 2 shows the deviatoric stress-strain curves of the Layer-Intact structure under different confining stresses. From Figure 2, it can be seen that the residual strength of different types of Layer-Intact structure increases with the increase of confining stress. When the fissure number is constant, the bearing capacity of the Layer-Intact structure increases with the increase of confining stress when the confining stress is within a certain range. When the confining stress reaches a certain critical value, microcracks will generate in the layer-crack specimen during the loading process. It is mean that the microcracks made early damage which leads to the reduction of the bearing capacity of the Layer-Intact structure and the stress fluctuation in the peak stress area. With the increase of fissure number, the bearing capacity of the Layer-Intact structure decreases, and the stress fluctuation phenomenon in the peak stress area is more obvious.

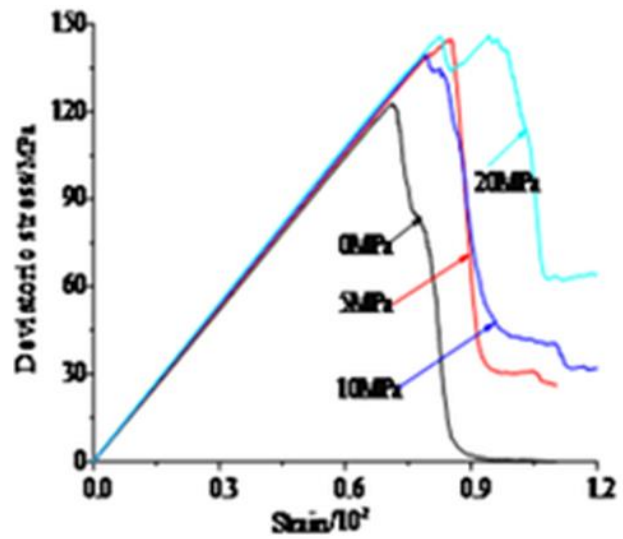

(a) one fissure

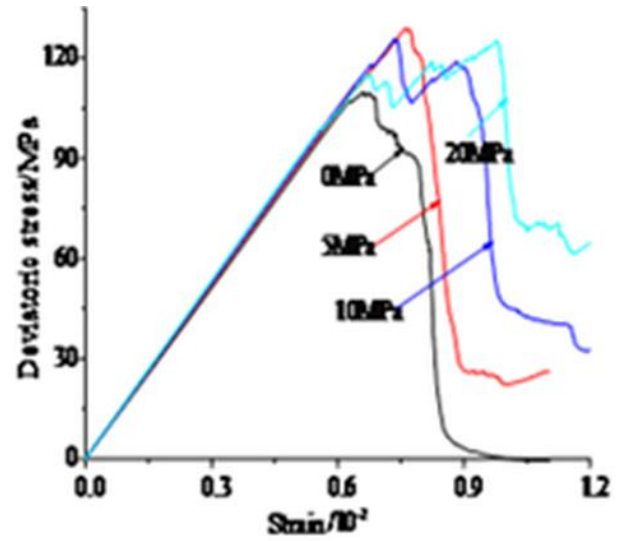

(b) two fissures 


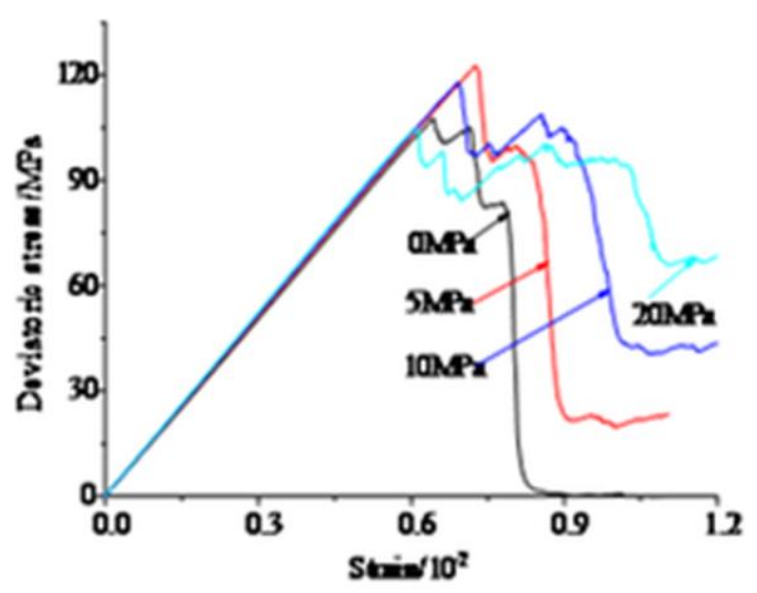

(c) Three fissures

Fig. 2. Stress-strain curves of two-body Layer-Intact structure specimen

Table 2 lists the mechanical properties of Layer-Intact structure specimens under different confining stresses. Figure 3 shows the relationship between the basic mechanical parameters and confining stress. According to Table 2 and Figure 3, confining stress and fissure number have a significant influence on the basic mechanical parameters of the Layer-Intact structure. In detail,(1) Under low confining stress, the peak stress of the whole specimen increases with the increase of confining stress, while under high confining stress, the peak stress tends to be stable or decrease with the increase of confining stress. For example, in the Layer-Intact structure with three fissures, when the confining stress increases from $0 \mathrm{MPa}$ to $5 \mathrm{MPa}$, the peak stress increases from $107.7 \mathrm{MPa}$ to $127.6 \mathrm{MPa}$, increasing by $18.48 \%$; When the confining stress increases from $5 \mathrm{MPa}$ to $20 \mathrm{MPa}$, the peak stress decreases to $104.6 \mathrm{MPa}$, decreasing by $18.03 \%$. (2)The elastic modulus increases slowly with the increase of confining stress, and the incremental value varies from $16.82 \mathrm{MPa}$ to $17.73 \mathrm{MPa}$, the variation law of the strain of peak stress is not obvious. (3)When the confining stress is constant, the peak stress of the whole specimen decreases with the increase of the fissure number. For example, when the confining pressure is $5 \mathrm{Mpa}$, the fissure number increases from 1 to 3 , the peak stress decreases from 144.9 $\mathrm{MPa}$ to $122.6 \mathrm{MPa}$, with a reduction rate of $15.39 \%$. The variation law of deformation parameters is not obvious.

Table 2. Mechanical parameters of the Layer-Intact structure specimen

\begin{tabular}{ccccc}
\hline Fissure number & $\begin{array}{c}\text { Confining stress } \\
/ \mathbf{M P a}\end{array}$ & $\begin{array}{c}\text { Peak stress } \\
/ \mathbf{M P a}\end{array}$ & $\begin{array}{c}\text { Elastic modulus } \\
/ \mathbf{G P a}\end{array}$ & $\begin{array}{c}\text { Peak strain } \\
\mathbf{1 0}^{-\mathbf{2}}\end{array}$ \\
\hline \multirow{3}{*}{1} & 0 & 122.6 & 16.89 & 0.714 \\
& 5 & 144.9 & 17.27 & 0.851 \\
& 10 & 139.5 & 17.42 & 0.790 \\
2 & 20 & 146.1 & 17.73 & 0.943 \\
\hline \multirow{3}{*}{3} & 0 & 109.7 & 16.96 & 0.662 \\
& 5 & 129.0 & 17.18 & 0.761 \\
3 & 10 & 125.8 & 17.27 & 0.735 \\
& 20 & 125.3 & 17.73 & 0.979 \\
\hline \multirow{3}{*}{3} & 0 & 107.7 & 16.82 & 0.644 \\
& 10 & 122.6 & 17.05 & 0.726 \\
\end{tabular}



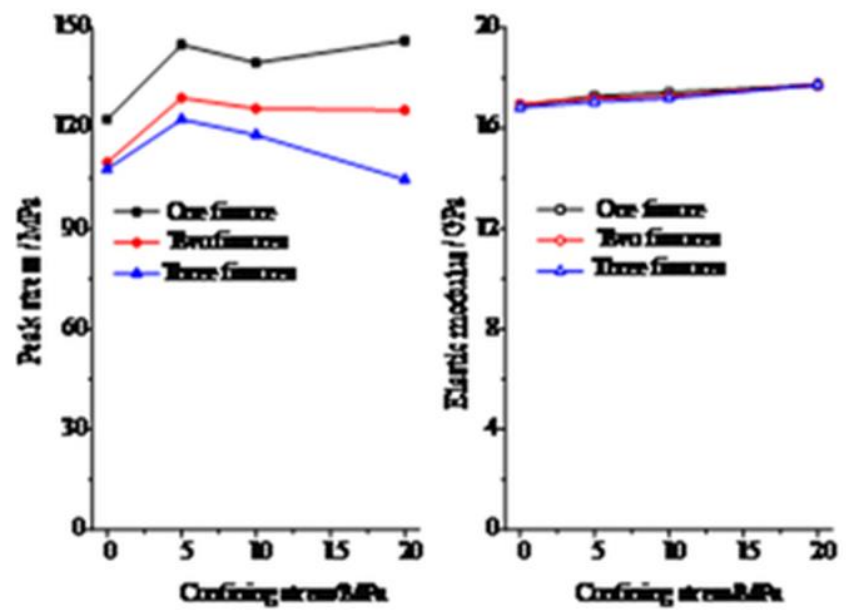

Fig. 3. the relationship between mechanical parameters and confining stress

Figure 4 shows the failure process of the specimen under the different confining stresses. It can be seen that the failure order is not affected by confining stress, and the layer-crack specimen is destroyed before the Intact specimen. When the fissure number is constant, the fragmentation degree of the whole specimen increases with the increase of confining stress, that is to say the confining stress enhance the destruction. When the confining stress is constant, the fragmentation degree of the whole specimen decreases with the increase of the fissure number.

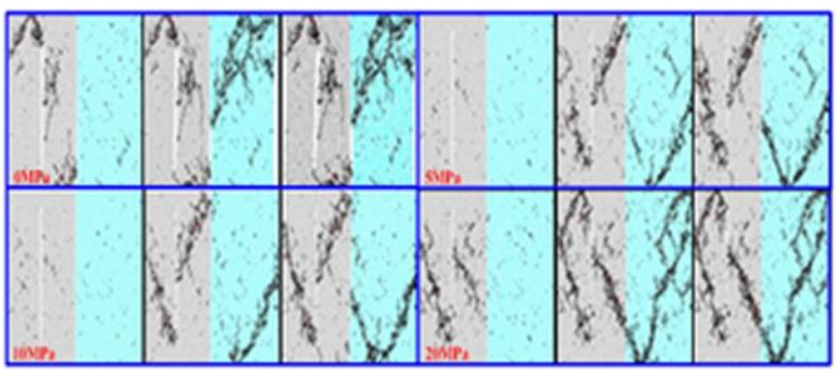

(a) One fissure

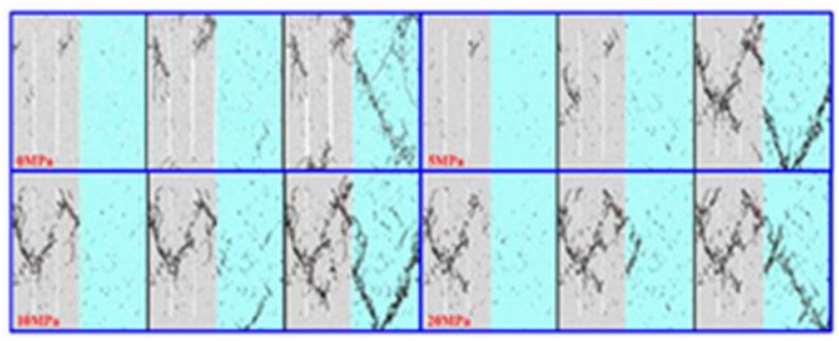

(b) Two fissures 


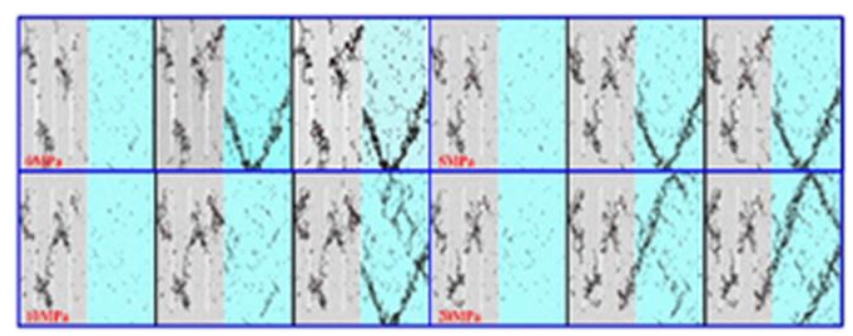

(c) Three fissures

Fig. 4. Failure process of the Layer-Intact structure

\subsection{Energy evolution law}

Fig. 5 shows the evolution law of strain energy during the process of deformation and failure of the specimen under different confining stress. It can be seen that in the initial and middle stages of loading, the rate of stored strain energy of the Layer-Intact structure increases gradually, and the rate of stored strain energy of the layer-crack specimen is familiar with the intact specimen. However, at the end of loading, because the Layer-crack specimen damaged firstly and the intact spencimen remained intact, the Layer-crack specimen began to release the strain energy, while the Intact specimen continued to store the strain energy, resulting in the fluctuation of the strain energy curve.The results show that the strain energy curve fluctuates, and the strain energy stored in Layer-Intact structure is released with the layer-crack specimen and the intact specimen as the failure occurs. This phenomenon shows that the dynamic instability of the layer-crack structure of roadway is not only the failure of shallow layer-crack coal mass, but also the participation of deep intact coal. When studying the dynamic instability mechanism of roadway, it is necessary to further clarify the participation degree of deep intact coal mass.

In addition, with the increase of confining stress, the energy storage capacity of Layer-Intact structure is enhanced with the increase of confining stress. But the proportion distribution of the strain energy in the structure is obviously affected by the confining stress. At the same confining stress, the energy storage capacity of the Layer-Intact structure decreases with the increase of the fissure number. 

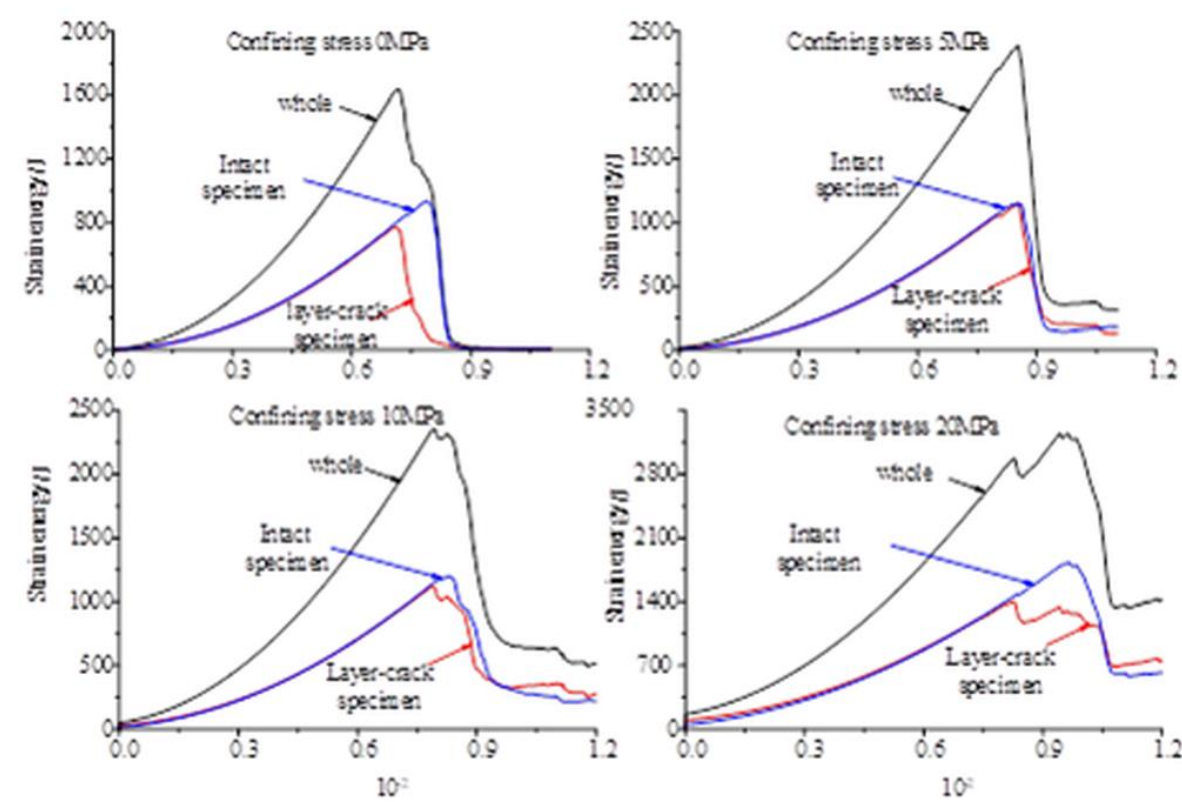

(a) One fissure
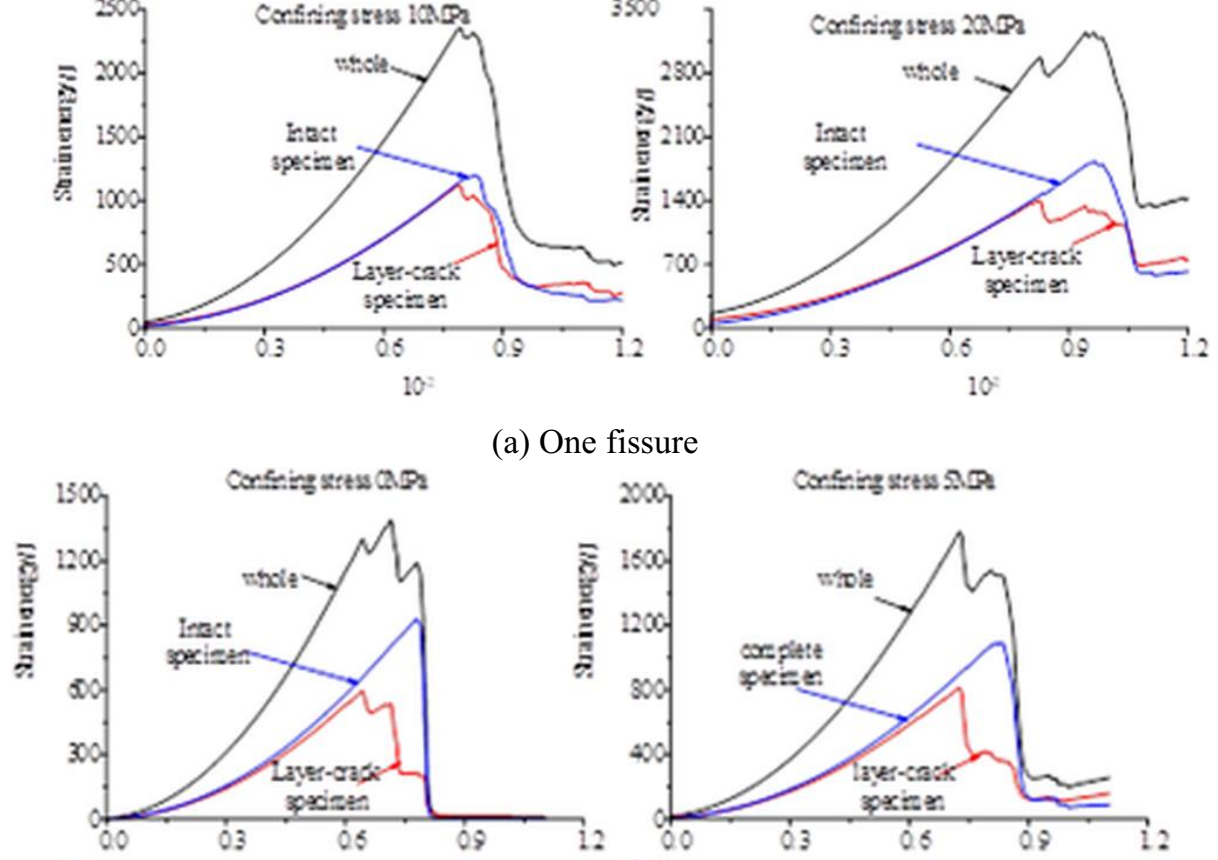

(b) Two fissures 

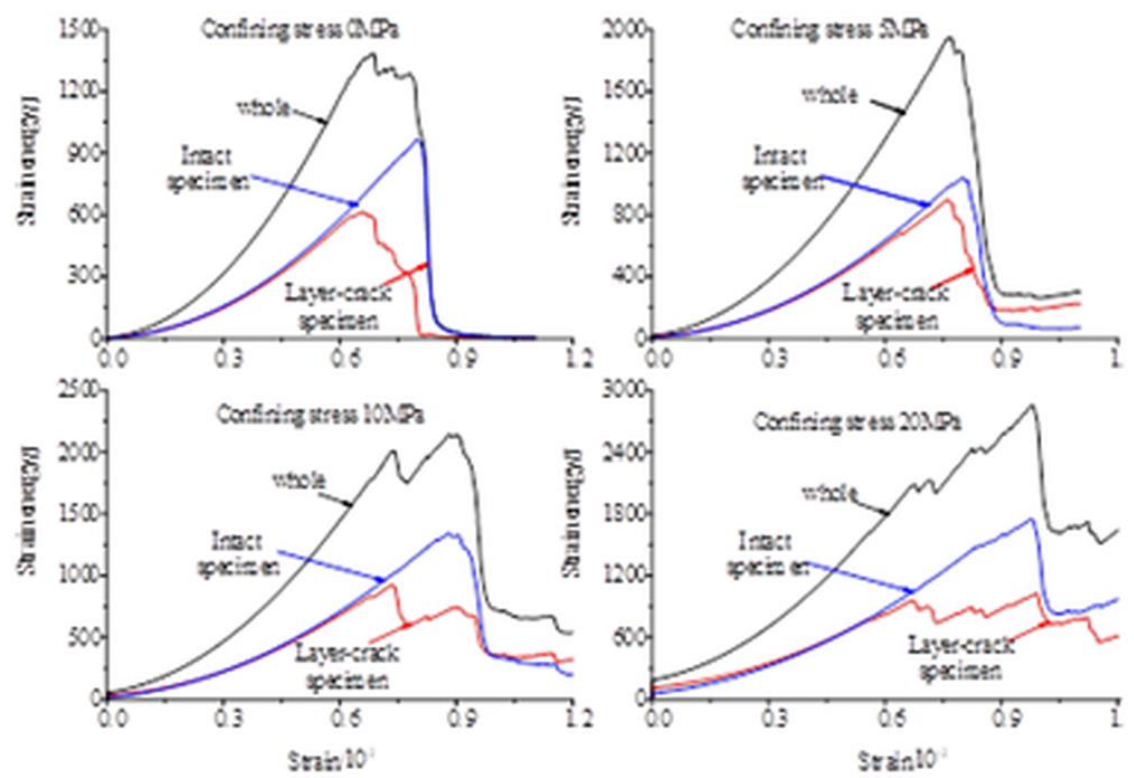

(c) Three fissures

Fig. 5. Strain energy evolution law of two-body Layer-Intact structure

In order to further analyze the variation of energy distribution with confining stress in the Layer-Intact structure, the maximum total strain energy stored in the two specimens in the Layer-Intact structure is normalized. The result shows in Fig. 6 (the energy ratio in the figure refers to the ratio of the maximum strain energy stored in the layer-crack specimen or intact specimen to the maximum total strain energy stored in the whole specimen).

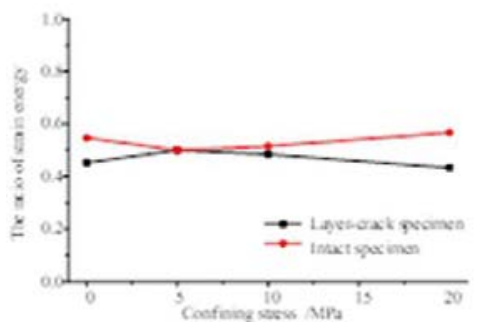

(a) One fissure

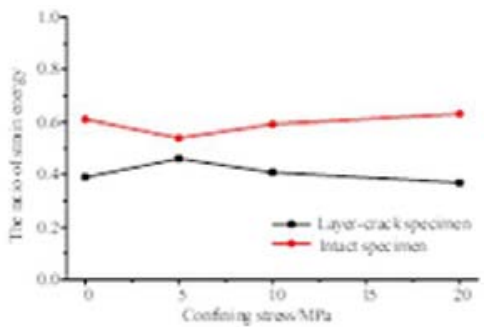

(b) Two fissures 


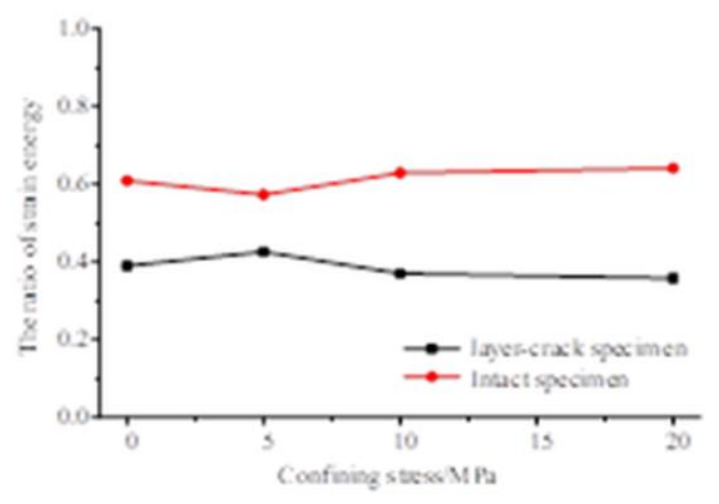

(c) Three fissures

Fig. 6 Energy allocation of two-body Layer-Intact structure

From Fig. 6, It can be seen that when the fissure number is constant, with the increase of confining stress, the energy ratio of layer-crack specimens increases first and then decreases, while that of intact specimens decreases first and then increases. For example, when the confining stress increases from $0 \mathrm{MPa}$ to $5 \mathrm{MPa}$, the energy ratio of the layer-crack specimen increases with one fissure from 0.45 to 0.50 , and when the confining stress increases from $5 \mathrm{MPa}$ to $20 \mathrm{MPa}$, the energy ratio of the layer-crack specimen increases from 0.50 to 0.43 . The reason is that when the confining stress is higher than a certain critical value, with the increase of confining stress, microcracks will appear in the layer-crack specimen in advance, and the damage degree is stronger than that of the intact specimen, which leads to the decrease of the energy ratio of the layer-crack specimen. Furthermore, it can be found that with the increase of the number of fissures, the bearing capacity and energy storage capacity of the Layer-Intact structure decrease, the energy ratio of the layer-crack specimen decreases and the energy ratio of the intact specimen increases. 


\section{Conclusion}

(1) In the two-body Layer-Intact structure, the layer-crack specimen always fails before the intact specimen. The damage degree of the composite structure is stronger than that of intact specimen. With the increase of the number of the fissure number, the bearing capacity of the composite structure decreases and the deformation inhomogeneity increases.

(2) The confining stress and the fissure have significant influence on the basic mechanical parameters of the two-body Layer-Intact structure. With the increase of confining stress, the peak stress of the two-body Layer-Intact structure increases first and then decreases.At the same confining stress, the peak stress of the two-body Layer-Intact structure decreases with the increase of the fissure number.

(3) The energy storage capacity of the Layer-Intact structure increases with the increase of confining stress. As the fussure number is constant, with the increase of confining stress, the energy ratio of layer-crack specimen increases first and then decreases, while that of intact specimen decreases first and then increases; As confining stress is constant; With the increase of fissure number, the bearing capacity of composite structure decreases, the energy ratio of layer-crack specimen decreases and the energy ratio of intact specimen increases.

\section{Acknowledgements}

The research described in this paper was financially supported by Major Scientific and Technological Innovation Project of Shandong Provincial Key Research Development Program (No.2019SDZY02), National Natural Science Foundation of China (No.51904165), Shandong Provincial Natural Science Foundation (No. ZR2019QEE026).

\section{References}

1. Z. Xiaochun, M.Xiexing, Z. Minghua, Chinese Journal of Rock Mechanics and Engineering, 17:5, 508 (1998)

2. W. Jiachen, Chinese Journal of Rock Mechanics and Engineering, 32:8, 785 (2007)

3. T. Yunliang, G.Weiyao, Z.Tongbin, Advances in Civil Engineering (2018)

4. Z. Tongbin, G. Weiyao, T. Yunliang, Advances in Mechanical Engineering, 9:11 (2017)

5. G.U. Xuebin, G. Weiyao, Z.Tongbin, S. Baotang, Z. Dongxiao, Journal of Shandong University of Science and Technology(Natural Science), 39:01, 46 (2020)

6. G. Weiyao, Y. Fenghai, T. Yunliang, Z. Tongbin, Energy Science \& Engineering, 7, 2351 (2019)

7. Z. Xiaochun, M. Xiexing, Chinese Journal of Rock Mechanics and Engineering, 21:11, 70 (2002)

8. L. Aihong, Y. Shi-lian, Q. Hao, Journal of China University of Mining and Technology, 37:6, 769 (2008)

9. P. Weihong, L. Aihong, Journal of Mining \& Safety Engineering, 25:2, 213 (2008)

10. Z. Xiaoping, L. Wong, International Journal of Fracture, 180:1, 93 (2013) 